Cahyaningtyas, H., Dale, A. A., Karimah, F. N., \& Caesaria, I. (2020). Kebahagiaan guru sekolah luar biasa (SLB). Indigenous: Jurnal Ilmiah Psikologi, 5(1). 93-102. doi:https://doi.org/10.23917/ indigenous.v5i1.11133

\title{
Kebahagiaan Guru Sekolah Luar Biasa (SLB)
}

\author{
Helga Cahyaningtyas ${ }^{1}$, Asti Asmerianingsih Dale ${ }^{2}$, \\ Fatihatun Nuroniyah Karimah ${ }^{3}$, Isma Caesaria ${ }^{4}$ \\ Magister Sains Psikologi, Universitas Muhammadiyah Surakarta ${ }^{1,2,3,4}$ \\ helgacahyaningtyas@gmail.com ${ }^{1}$, asthi.aningsih@gmail.com ${ }^{2}$, \\ fatih.nuroniyah@gmail.com ${ }^{3}$
}

\begin{abstract}
Abstrak. Kebahagiaan guru SLB ialah suatu kondisi psikologiss yang mampu memberikan kedamaian, rasa bahagia, memahami makna dan tujuan serta kesejahteraan hidup dalam menjalankan peran sebagai guru SLB. Penelitian ini bertujuan memperoleh pemahaman \& mengkaji secara mendalam mengenai gambaran kebahagiaan guru SLB. Penelitian ini menggunakan pendekatan kualitatif fenomenologi. Partisipan sebanyak empat orang dengan kriteria yaitu guru tetap di SLB-C YPSLB. Wawancara dan observasi digunakan sebagai metode pengumpulan data. Hasil penelitian menunjukkan bahwa kebahagiaan guru SLB selama mengajar diperoleh dari pikiran positif, emosi positif, dan kepuasan. Kebahagiaan guru SLB dipengaruhi oleh relasi sosial, religiusitas, dan pendapatan.
\end{abstract}

Katakunci: emosi positif; guru SLB; kebahagiaan; kepuasan; pikiran positif

Abstract. The happiness of a SLB teacher is a psychological condition that is able to provide peace, happiness, understanding the meaning and purpose and welfare of life in carrying out the role of a SLB teacher. This study aims to gain an understanding \& examine in depth about the picture of the happiness of SLB teachers. This study used a qualitative phenomenological approach. Participants were four people with the criteria of permanent teachers in YPSLB SLB-C. Interview and observation are used as data collection methods. The results showed that the happiness of SLB teachers during teaching was obtained from positive thoughts, positive emotions, and satisfaction. The happiness of SLB teachers is influenced by social relations, religiosity, and income.

Keywords: positive emotions; SLB teacher; happiness; satisfaction; positive thinking

\section{PENDAHULUAN}

Anak Berkebutuhan Khusus (ABK) ialah anak yang dalam masa pertumbuhan \& perkembangannya mengalami adanya penyimpangan /kelainan fisik, penyimpangan mental (intelektual), penyimpangan emosional, dan atau penyimpangan sosial dibanding dengan anak-anak lain yang seusianya, sehingga membutuhkan pelayanan pendidikan khusus (Jannah \& Darmawanti, 2004).

Data yang diperoleh dari Badan Pusat Statistik (BPS) tahun 2017 menunjukkan bahwa anak berkebutuhan khusus (ABK) di Indonesia berjumlah sekitar 1,6 juta anak. Berdasarkan data tersebut, Kementerian Pendidikan dan Kebudayaan Republik Indonesia melakukan salah satu upaya dengan memberikan pelayanan pendidikan untuk anak berkebutuhan khusus, yaitu mendirikan unit sekolah baru, berupa Sekolah Luar Biasa (SLB) maupun mendorong berdirinya 
Sekolah Inklusi di daerah-daerah (Maulipaksi, 2017).

Proses pembelajaran di sekolah luar biasa melibatkan guru sebagai tenaga pendidik. Saat ini pekerjaan sebagai guru menimbulkan berbagai tanggapan masyarakat, sebagian masyarakat beranggapan bahwa pekerjaan, dan beban tugas guru sekarang tidak mewujudkan karir guru yang menarik (Wardhani, 2012). Peraturan Pemerintah RI No 72 Tahun 1991 mengenai Pendidikan Luar Biasa pasal 20 ayat (2) menjelaskan bahwasanya tenaga pengajar pada satuan pendidikan luar biasa ialah tenaga pengajar yang mempunyai persyaratan khusus sebagai guru di satuan pendidikan luar biasa (Peraturan Pemerintah no. 72, 1991).

Tenaga pendidik atau guru SLB dituntut untuk selalu bersikap profesional dengan kompetensi yang berbeda dengan guru sekolah umum. Semua guru SLB wajib diberikan materi keprofesian kependidikan, agar mempunyai kompetensi yang dibutuhkan dalam melaksanakan tugas pokok dan fungsinya secara efektif \& efisien (Hamalik, 2003). Rosdiana (2013) menyatakan bahwa menjadi guru pada sekolah luar biasa tidak sama seperti guru pada sekolah umum, guru dituntut untuk ikhlas, sabar dan tekun dalam memberikan pelajaran maupun ketika menghadapi siswa, guru sebaiknya menganggap siswa seperti anak sendiri. Guru SLB harus mampu memahami apa yang diinginkan siswanya. Guru juga harus bisa memahami karakter setiap siswa karena sifat siswa sekolah luar biasa sangat sensitif, sehingga dalam pendekatannya perlu kesabaran \& keikhlasan.

Wardhani (2012) menjelaskan bahwa perilaku koping mempunyai hubungan negatif dengan burnout yang dirasakan guru SLB, kepuasan kerja mempunyai hubungan negatif dengan burnout yang dirasakan guru SLB, perilaku koping dan kepuasan kerja sama-sama bisa memprediksi terjadinya burnout pada guru SLB. Irianto dan Subandi (2015) menjelaskan bahwa pengalaman guru selama mengabdi dapat mengarahkan perasaannya ke hal-hal yang positif. Seperti saat siswa-siswa yang ada di pedalaman mampu mengikuti pelajaran sekolah, siswa dapat melanjutkan sekolah ke jenjang yang lebih tinggi, terjalinnya kesatuan kerja antar guru di pedalaman dan adanya dukungan sebagai guru dari masyarakat setempat maupun keluarga.

Menurut Hamama dkk. (2013) pengendalian diri dan dukungan sosial organisasi pada guru SLB memberikan pengaruh positif dan kepuasan hidup pada guru SLB. Dukungan organisasi diketahui dapat memoderasi hubungan antara stress dan pengaruh negatif, serta hubungan antara stress dan pengaruh positif \& kepuasan hidup di antara para guru. Hasil tersebut memberikan kontribusi terhadap peran guru dalam membangkitkan kesejahteraan subjektif, kebahagiaan, kepuasan hidup, maupun problem solving guru SLB.

Kebahagiaan ialah suatu emosi positif secara subjektif yang mampu mempengaruhi masingmasing individu dalam memaknai setiap peristiwa yang terjadi di kehidupan (Lopez, Pedrotti, \& Syender, 2007).

Aziz (2011) menyatakan bahwa transfer ilmu dari guru kepada siswa ditentukan oleh rasa bahagia yang dirasakan guru. Ketika guru mengajar dengan bahagia, guru mampu mengimbangi cara maupun kecepatan berpikir siswa, sehingga ilmu dapat merasuk ke dalam jiwa. Guru akan menyesuaikan dirinya agar siswa bisa menerima ilmu yang dimiliki secara efektif.

Berprofesi sebagai guru SLB dituntut untuk selalu senang \& nyaman sehingga guru mampu menikmati kehidupan. Jika pekerjaan dapat dinikmati, maka akan menciptakan rasa puas dengan kehidupan yang dijalani tanpa merasa terbebani. Kehidupan yang baik ialah ketika seseorang menyukai \& bersyukur atas kehidupannya (Gunawan, Halim, \& Lihardja 2011). Menurut Patnani (2012) unsur-unsur yang mendukung kebahagiaan ialah adanya pikiran positif dan pengendalian diri. Penelitian ini bertujuan untuk mengkaji \& memperoleh pemahaman secara 
mendalam mengenai gambaran kebahagiaan guru SLB.

Secara umum kebahagiaan adalah pengalaman internal tentang pikiran positif yang dapat diperoleh melalui berbagai cara dalam kehidupan sehari-hari (Lu \& Shih, 1997). Kebahagiaan merupakan pengertian umum yang menampakkan adanya kenikmatan atau kepuasan dalam lingkup kesejahteraan, keamanan, atau terwujudnya semua keinginan. Kebahagiaan merupakan tujuan utama kehidupan manusia. Kebahagiaan adalah rasa puas, tenang, ketentraman batin, atau tentrem ing manah, tidak adanya ketegangan. Kebahagiaan tidak hanya suatu afeksi atau kondisi yang menyenangkan, namun suatu keadaan yang meningkatkan taraf hidup, sehat secara fisik, tercapainya potensi seseorang. Suatu afeksi bahagia adalah tanda keberhasilan seseorang secara nyata dalam hidupnya (Indriana, 2012).

Aziz (2011) menjelaskan bahwa tingkat pengalaman spiritual yang dimiliki seseorang dapat berhubungan dengan adanya kepuasan hidup dan kebahagiaan, pengembangan kepuasan hidup dan kebahagiaan para guru akan meningkat sejalan dengan meningkatnya spiritualitas. Seseorang yang merasa lebih bahagia akan memiliki perasaan optimis yang tertanam didalam dirinya (Nandini, 2016).

Menurut Robbins (2008), pendekatan psikologi positif memiliki tiga gagasan utama terkait kebahagiaan. Pertama adalah pengalaman subjektif secara positif berupa adanya tingkat kemakmuran, perasaan tertarik, rasa senang, rasa optimis, dan penuh harap. Kedua, kondisi kepribadian seseorang yang sedang mengalami tumbuh-kembang, seperti sikap berani, tekun, arif, dan keterbukaan. Ketiga, peran lingkungan dalam mendukung pengalamn subjektif yang positif serta menumbuhkan pribadi yang adaptif.

Pendekatan psikologi positif menjelaskan adanya banyak faktor yang mempengaruhi tingkat kebahagiaan seseorang diantaranya adalah kemampuan bersyukur, optimisme, kemampuan mencintai, keharmonisan keluarga, kepuasan hidup, dan lain sebagainya (Seligman, 2005).

Menurut Seligman (2011), authentic happiness dianalisis menjadi tiga elemen yaitu emosi positif, keterlibatan, dan makna. Emosi positif meliputi apa yang dirasakan seseorang terkait rasa senang, rasa hangat, rasa nyaman, penghargaan, dan sejenisnya. Keterlibatan berupa aliran perasaan yang berperan langsung seperti menyatu dengan musik, waktu terasa berhenti, bahkan hilangnya kesadaran diri selama kegiatan berlangsung. Elemen makna yaitu sebagai jalur akhir untuk mengejar kebahagiaan, penemuan makna dalam hidup menentukan tingkat kebahagiaan.

Seligman (2005) mengatakan bahwa kebahagiaan yang asli (authentic happiness) terbagi menjadi tiga aspek yaitu aspek perasaan senang dan puas, aspek wujud dari kekuatan dan kebaikan, serta aspek makna dan tujuan. Aspek kebahagiaan menurut Diener dan Scollon (2003) yaitu aspek emosional dan kognitif.

Menurut Indriana (2012), aspek kebahagiaan yaitu: 1) Adanya rasa senang dalam melakukan aktivitas sehari-hari; 2) Menganggap hidupnya penuh makna dengan adanya penerimaan secara tulus terhadap kondisi kehidupannya; 3) Merasa mencapai hasil yang optimal dalam meraih cita-cita atau tujuan hidup; 4) Memiliki penilaian diri yang positif; 5) Bersikap optimis dan selalu bahagia.

Kajian yang berkaitan dengan variabel kebahagiaan telah dilakukan oleh Irianto dan Subandi (2015), bertujuan untuk mengkaji dan menganalisis secara mendalam nilai-nilai kebahagiaan serta mengeksplorasi karakter positif yang diwujudkan dalam proses belajarmengajar di pedalaman Papua. Hasil penelitian diperoleh bahwa guru menunjukkan perasaannya ke hal-hal yang positif berdasarkan pengalaman selama mengabdi. 
Selanjutnya penelitian serupa telah dilakukan oleh Patnani (2012) dengan tujuan untuk menganalisis gambaran kebahagiaan pada perempuan berupa tingkat kebahagiaan, sumber kebahagiaan dan unsur kebahagiaan, berlandaskan perbedaan umur, status pernikahan, dan pekerjaan. Hasil penelitian menunjukkan bahwa unsur-unsur yang mendukung kebahagiaan adalah adanya pikiran positif dan pengendalian diri.

Berdasarkan penelitian yang relevan tersebut, peneliti ingin mengkaji lebih dalam makna kebahagiaan pada guru SLB. Pertanyaan penelitian ini, 1) Bagaimana gambaran kebahagiaan pada guru SLB?; 2) Apa saja faktor yang mempengaruhi kebahagiaan pada guru SLB?

\section{METODE}

Penelitian menggunakan pendekatan kualitatif dengan metode fenomenologi. Peneliti berusaha untuk menemukan makna/arti dari sebuah fenomena yang terjadi pada beberapa individu dengan menggali informasi secara mendalam dan komprehensif mengenai gambaran kebahagiaan yang dirasakn oleh guru SLB.

Penelitian ini terselenggara di SLB-C YPSLB Surakarta. Durasi waktu pelaksanaan penelitian selama 1,5 bulan terhitung mulai bulan Oktober-November 2017. Informan berjumlah 4 orang. Teknik pengambilan subjek menggunakan teknik purposive sampling dengan kriteria informan yaitu guru tetap di SLB-C YPSLB Surakarta dan bersedia menjadi informan. Teknik yang digunakan untuk mengumpulkan data adalah wawancara semi terstruktur dan observasi non partisipan. Panduan wawancara berisi pertanyaan-pertanyan secara garis besar untuk mengungkap gambaran kebahagiaan guru SLB. Observasi dilakukan di lingkungan SLB-C YPSLB Surakarta.

Penelitian ini melakukan uji keabsahan data menggunakan uji kredibilitas dan uji dependabilitas. Teknik analisis data dilakukan melalui tahapan yaitu menyiapkan data dan mengolahnya, membaca seluruh data yang diperoleh, menganalisis secara rinci dengan mengodekan data, melakukan proses koding, mendeskripsikan dan menentukan tema-tema, menginterpretasikan data atau memaknai data (Creswell, 2010).

\section{HASIL DAN PEMBAHASAN}

\section{Gambaran Kebahagiaan}

Kebahagiaan guru SLB dapat dirasakan dengan cara memiliki pikiran positif, emosi positif dan memiliki kepuasan. Pikiran positif, seperti memberi semangat, memberi harapan hidup, memiliki keunggulan dibanding Guru sekolah umum, ingin membantu, mendapat pengalaman yang mengesankan, memberi pengajaran agar siswa mandiri dan mengabdi. Emosi positif, seperti merasa senang, keceriaan, tidak bosan, rindu pada siswa, hati yang tersentuh, menerima, memberikan ketulusan dan kesabaran. Kepuasan, dirasakan dengan cara melihat perkembangan kemampuan anak, prestasi anak dan bangga.

Guru SLB memiliki pandangan mengenai aktifitas pekerjaan yang dilakukan di sekolah. Guru SLB memandang anak berkebutuhan khusus sebagai seseorang yang memiliki keterbatasan dalam menjalankan kehidupannya baik dalam hal fisik dan psikologis. Pemikiran yang muncul bahwa anak berkebutuhan khusus merupakan orang yang perlu mendapatkan sentuhan kasih sayang, harapan, pendidikan dan pertolongan agar memperoleh derajat yang sama dimata masyarakat, tidak memiliki harga diri yang rendah dan dapat menjalankan kehidupan secara mandiri. Kebahagiaan mencakup perasaan positif seperti kegembiraan dan kenyamanan. 
Kebahagiaan dapat diperoleh dengan cara menilai dan memaknai hidup sebagai hal yang berharga, memahami diri sendiri, dan menemukan energy positif atau kelebihan dalam diri, kemudian mengembangkan dan menerapkan kelebihan tersebut untuk kegiatan yang positif (Seligman, 2005). Penelitian yang dilakukan oleh Mertoğlu (2018), menunjukkan bahwa secara umum seorang guru merasakan senang atau bahagia ketika menjalankan perannya sebagai guru. Berdasarkan data dari 4 informan penelitian diperoleh hasil yang dapat dilihat pada gambar 1.

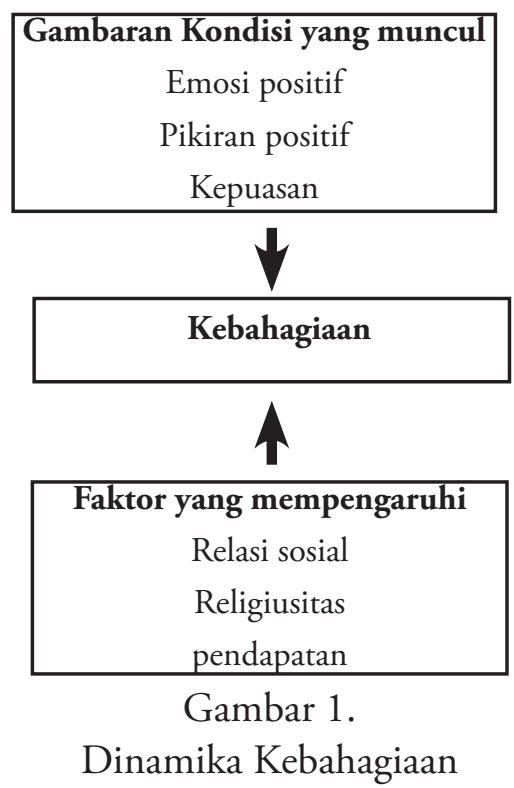

Pikiran yang positif dan kontrol diri merupakan bagian yang konsisten untuk mencapai kebahagiaan (Patnani, 2012). Sejalan dengan pendapat Lu dan Shih (1997), bahwa kebahagiaan adalah pengalaman internal tentang pikiran positif yang bisa diperoleh melalui berbagai cara di dalam kehidupan sehari-hari . Menurut Veenhoven (1991), kebahagiaan dapat dipahami sebagai tingkat bagaimana seorang individu menilai kualitas hidupnya secara keseluruhan. Dengan kata lain seberapa baik seseorang menyukai kehidupan yang dijalaninya.

Siswa SLB-C dengan segala keterbatasan yang dimiliki membuat guru tersentuh dan terpanggil jiwanya untuk membantu dalam hal pendidikan. Perasaan (emosi) positif pada guru SLB selama mengajar merasakan cinta dan ketulusan pada siswa, hal ini membuat seorang guru menganggap seperti anak sendiri. Perasaan cinta kepada siswa terlihat dari perasaan rindu kepada siswa jika tidak bertemu, menerima segala kondisi siswa dan merasa nyaman jika berada di Sekolah. Seligman (2005) menjelaskan kebahagiaan adalah konsep yang mengarah pada emosi positif yang dirasakan individu serta kegiatan-kegiatan positif yang disenangi oleh individu. Adapun kebahagiaan pada guru selalu merasakan perasaan atau emosi positif kepada siswanya dan berkontribusi untuk menjadi contoh dalam melakukan pembelajaran yang menyenangkan. Dengan begitu, kebahagiaan tersebut ada hubungan yang bersinergi dan positif antara guru maupun siswanya (Meiza, 2016).

Berbagai karakteristik kemampuan siswa dalam mengikuti proses belajar tidak membuat guru putus asa. Guru menyadari bahwa keterbatasan siswa dalam memahami materi dan berbagai karakteristik yang dimiliki membuat guru harus memiliki berbagai cara untuk mengajar. Guru SLB mampu memahami karakter masing-masing siswa sehingga guru tidak mengalami kesulitan dan kebosanan dalam mengajar. Bahkan ketika guru dihadapkan pada situasi dimana tidak memiliki ilmu dalam bidang keterampilan, seorang guru justru merasa senang belajar secara otodidak untuk diajarkan kepada siswa. Kebahagiaan tidak hanya menyangkut mengenai 
afeksi atau kondisi yang menyenangkan namun juga suatu bentuk kondisi untuk meningkatkan kualitas hidup yang termasuk pengembangan potensi diri dan pemenuhan kesehatan fisik individu (Indriana, 2012). Menurut Seligman (2005), kebahagiaan merupakan perasaan atau emosi positif dan kegiatan positif. Kegiatan positif yaitu kesenangan dan keterlibatan dalam melakukan aktivitas masa kini. Sejalan dengan hasil penelitian bahwa informan merasa senang dalam menjalankan tanggungjawab sebagai seorang guru meskipun siswa mengalami kesulitan dalam belajar dan dituntut untuk belajar secara mandiri di luar dari keahlihan yang dimiliki.

Kepuasan pada guru SLB yaitu berkaitan dengan kepuasan dalam mencapai tujuan untuk membantu membina siswa SLB menjadi lebih baik. Guru SLB merasa puas dengan profesi yang dijalaninya ketika dapat berhasil mendidik siswa SLB. Keberhasilan yang dimaksud misalnya terlihat dari siswa sudah mampu patuh terhadap perintah yang diberikan guru. Guru SLB merasakan kepuasan karena memiliki problem solving yang baik atau mampu menyelesaikan masalah/ kesulitan yang berkaitan dengan pekerjaanya dalam menangani anak berkebutuhan khusus, sehingga dapat memaknai dengan positif dari peristiwa yang dialami, mampu mengelola diri, mampu bersikap sabar dalam memahami siswanya. Kepuasan yang menyenangkan, keamanan, kenyamanan serta adanya pemenuhan keinginan menunjukkan bahwa seseorang bahagia. Kebahagiaan adalah rasa puas, tenang, ketentraman batin atau tentrem ing manah, tidak adanya ketegangan. Suatu perasaan bahagia merupakan bukti keberhasilan seseorang dalam hidupnya (Indriana, 2012). Toisuta dan Loekmono (2017), menyatakan bahwa secara umum kepuasan pada ranah kehidupan yang spesifik menggambarkan adanya perasaan kebahagiaan pada individu.

Menurut Urrutia dkk. (2019), kebahagiaan didefinisikan sebagai kondisi kesejahteraan, mental atau emosional, yang melibatkan emosi positif atau perasaan senang seperti kepuasan. Penelitian sebelumnya Wulandari dan Widyastuti (2014), menyatakan seseorang yang bekerja dengan sungguh-sungguh dan pantang menyerah akan merasakan kepuasan dalam pekerjaan, sehingga akan merasa senang hati dalam melakukan pekerjaan. Hal tersebut sesuai dengan ke empat informan yang merasakan kepuasan dalam mengajar karena bekerja dengan kesabaran dan ketelatenan demi keberhasilan siswa-siswinya dalam hal kemandirian.

\section{Faktor-Faktor Kebahagiaan}

Tabel 1.

Faktor-Faktor Kebahagiaan

\begin{tabular}{ll}
\hline \multirow{2}{*}{ Relasi sosial } & - Kedekatan dengan siswa. \\
& - Kedekatan dengan wali murid, support antar rekan guru dan kepada masyarakat dalam mem- \\
& beri pemahaman sekolah luar biasa. \\
\hline Religiusitas & Ikhlas, bersyukur kepada Allah, doa dan percaya akan balasan dari sang Pencipta. \\
\hline Pendapatan & Merasa gaji yang diperoleh lebih dari cukup \\
\hline
\end{tabular}

Relasi sosial yang terjalin pada semua informan terdiri dari interaksi sosial antara siswa dan guru, guru dengan wali murid, guru dengan masyarakat dan guru dengan guru. Interaksi sosial yang terjalin antara guru SLB dan siswa terbentuk selama siswa masih sekolah bahkan hingga siswa lulus sekolah. Guru SLB menganggap siswanya sebagai bagian yang menyatu dalam hidupnya, memperlakukan siswanya seperti saudara sehingga muncul adanya rasa rindu antara guru dan siswa. Bentuk kedekatan antara siswa kepada guru diantaranya selalu menyapa, sering merangkul guru, mengunjungi rumah guru untuk bersilaturahmi dan ingin selalu dibimbing oleh guru yang disukai selama di kelas. 
Interaksi yang terbentuk antara guru dengan guru dalam lingkungan sekolah seperti adanya rasa saling menghargai, menghormati dan tidak saling membandingkan kemampuan dalam menciptakan perasaan nyaman di sekolah. Interaksi antara guru dengan orangtua juga merupakan hal penting dalam memberikan pemahaman yang positif mengenai anak berkebutuhan khusus di SLB. Hal ini memberikan dampak positif pada orangtua yang memiliki ABK dengan guru SLB seperti saling berbagi dengan senang dan akrab. Selain itu, bentuk interaksi guru dengan masyarakat terlihat dari guru memberikan pemahaman mengenai SLB pada masyarakat dengan memberi pengetahuan yang baik mengenai fungsi SLB. Pemahaman masyarakat yang negatif mengenai SLB menjadi positif dan menyadari bahwa SLB merupakan pendidikan yang dibutuhkan terutama untuk masyarakat yang memiliki anak berkebutuhan khusus. Hal tersebut sesuai dengan pernyataan Primasari dan Yuniarti (2012), bahwa menjalin hubungan interaksi sosial dengan orang lain merupakan salah satu faktor yang dapat membuat seseorang bahagia. Sejalan dengan pendapat Rofi'udin (2013), hubungan emosional yang positif dengan orang lain merupakan suatu sumber kebahagiaan. Hal ini dikarenakan adanya sikap saling membutuhkan satu sama lain untuk menjaga hubungan yang harmoni dengan yang lain (Wulandari dan Widyastuti, 2014).

Selain itu salah satu faktor lainnya yang mempengaruhi kebahagiaan adalah religiusitas, yaitu kegiatan yang berkaitan dengan ajaran agama. Menurut Irianto dan Subandi (2015), ajaran agama dan keyakinan kepada Tuhan Yang Maha Esa merupakan satu kekuatan karakter yang diterapkan karena dapat memperoleh kebahagiaan, sekalipun berada dalam situasi yang tidak menyenangkan. Salah satu satu problem solving yang dilakukan oleh guru SLB ialah dengan bersikap pasrah, berdoa dan mendekatkan diri kepada Tuhan untuk mencari solusi terkait permasalahan yang dihadapi siswa di sekolah, dengan harapan suatu saat siswa dapat menjalankan hidupnya secara mandiri. Pernyataan diatas didukung dalam studi lintas budaya, hal tersebut menunjukkan bahwa orang bahagia adalah mereka yang memiliki kepercayaan diri, spiritualitas, dan keyakinan pada agamanya yang tinggi (Rofi'udin, 2013).

Nilai keagamaan yang dilakukan informan yaitu bersyukur atas karunia ilmu pendidikan dan kondisi fisik normal yang diberikan Tuhan, sehingga dimanfaatkan dengan mengajarkan nilai-nilai agama kepada siswa seperti berdoa sebelum dan setelah pelajaran. Dengan berpegang kepada agama dalam menjalankan pekerjaannya, guru SLB menganggap bahwa mendidik siswa sebagai bentuk ibadah yang akan menjadi bekal untuk menghadap Sang Pencipta.

Penelitian sebelumnya oleh Darokah dan Diponegoro (2005), menjelaskan bahwa terdapat pengaruh positif nilai religiusitas terhadap kepuasan hidup dan afek Islam berkenaan dengan kebahagiaan dalam aktivitas keagamaan (religiusitas) seperti meningkatkan ketaqwaan kepada Allah dan melakukan aktivitas yang membangun sehingga menjalin hubungan dengan manusia. Hal tersebut juga sependapat dengan Aziz (2011), bahwa upaya yang dilakukan untuk meningkatkan kebahagiaan para guru adalah dengan meningkatkan aspek spiritual dalam dirinya. Dalam agama Islam, selama ini sebagian besar umat manusia mencari kebahagiaan tidak hanya berupa pencapaian yang bersifat material saja tapi juga melibatkan aspek spiritual. Islam sebagai suatu ajaran agama yang sangat menganjurkan umatnya untuk selalu senantiasa membangun hubungan antara dirinya dengan Allah (hablum minallah) dan kemampuan dalam membangun hubungan antar sesama manusia (hablum minannas).

Pendapatan atau gaji juga merupakan faktor kebahagiaan selain relasi sosial dan religiusitas. Informan bekerja sebagai guru SLB salah satunya atas dasar mengharapkan imbalan untuk memenuhi kebutuhan keluarganya dan tuntutan kehidupan. Gaji yang diterima informan dianggap sudah lebih dari cukup yang berarti tingkat pendapatan yang diperoleh guru SLB 
sudah memuaskan. Pada penelitian sebelumnya menunjukkan bahwa masyarakat yang memiliki penghasilan yang rendah tidak dapat mencukupi kebutuhan pokok sehari-harinya sehingga berpengaruh terhadap kondisi sosialnya. Selain itu tidak mendapat kepuasan dalam hidup dan cenderung merasa tidak bahagia. Sebaliknya pada masyarakat yang memiliki penghasilan tinggi, mereka mampu memenuhi kebutuhan-kebutuhannya. Selain itu mendapatkan kepuasan dalam hidup dan cenderung merasa bahagia (Damongilala dkk., 2014). Dari pernyataan diatas, hal tersebut menunjukkan bahwa hasil penelitian yang telah dilakukan berbeda dengan hasil penelitian sebelumnya, yang mana informan dalam penelitian ini merasakan kepuasaan terhadap pendapatan yang di peroleh.

Sejalan dengan hasil penelitian ini, hasil penelitian Hapsari dan Mardiana (2016) juga ditemukan bahwa guru yang memiliki motivasi tinggi pada pekerjaannya dapat merasakan dan memahami kondisi yang dialami oleh siswanya. Selain itu, guru dengan motivasi kerja yang tinggi akan berpengaruh ke produktivitas pekerjaannya dalam mengajar, sehingga guru akan lebih mudah mengajar dan mendidik tanpa mementingkan faktor lain seperti gaji dan lingkungan kerja yang behubungan dengan kondisi dalam mengajar. Dapat diartikan bahwa guru SLB cukup dengan pengahasilan yang diperolehnya dan dapat mengajar ABK tanpa merasa terbebani.

\section{SIMPULAN}

Berdasarkan hasil penelitian, dapat disimpulkan bahwa gambaran kebahagiaan pada guru SLB terlihat dari adanya pikiran dan emosi yang positif guru SLB dalam memandang siswa SLB maupun pekerjaannya sebagai guru SLB. Adanya peningkatan perkembangan pada siswasiswi merupakan suatu kepuasan bagi para guru SLB. Emosi dan pikiran yang positif maupun kepuasaan yang di rasakan oleh guru SLB terjadi karena adanya hubungan emosional guru SLB dengan siswanya, serta adanya hubungan baik antara guru SLB dan orangtua maupun masyarakat di sekitar. Hal lain yang mempengaruhi kebahagiaan pada guru SLB meliputi adanya nilai-nilai religiusitas yang berkaitan dengan ketaqwaan kepada Allah dan aktivitas yang berkaitan dengan manusia.

Saran bagi peneliti selanjutnya adalah perlu dilakukan beberapa kali wawancara atau dapat menggunakan metode pengambilan data dengan survey/angket terbuka yang ditujukan kepada guru SLB sehingga mendapatkan hasil yang lebih mendalam dan menyeluruh mengenai gambaran kebahagiaan pada guru SLB karena metode survey dapat mencangkup jumlah subyek yang lebih besar daripada wawancara sehingga hasilnya dapat di generalisasikan.

Sedangkan saran untuk guru SLB adalah untuk selalu fokus pada tujuan, senantiasa optimis, bersabar dan meningkatkan rasa syukur dalam menghadapi serta mengatasi segala kesulitan sehingga dapat menumbuhkan rasa bahagia dan membangkitkan motivasi diri dalam menjalani keseharian sebagai pengajar anak berkebutuhan khusus di SLB.

\section{REFERENSI}

Aziz, R. (2011). Pengalaman spiritual dan kebahagiaan pada guru Agama Sekolah Dasar. Jurnal Proyeksi, 6(2), 1-11. https://doi.org/10.30659/p.6.2.1-11

Creswell, J. W. (2010). Research design pendekatan kualitatif, kuantatif, dan mixed. Yogyakarta: Pustaka Pelajar. 
Damongilala, S., Opod, H., \& Sinolungan, J. S. V. (2014). Hubungan status sosial ekonomi dengan kebahagian keluarga dalam masyarakat Desa Betelen 1 Kecamatan Tombatu Kabupaten Minahasa Tenggara. Jurnal e-Biomedik, 2(2), 467-470. https://doi. org/10.35790/ebm.2.2.2014.5000

Darokah, M., \& Diponegoro, A. M. (2005). Peran akhlak terhadap kebahagiaan remaja Islam. Indonesian Psychological Journal, 2(1), 15-27. http://journal.uad.ac.id/index.php/ HUMANITAS/article/view/312

Diener, E., \& Scollon, C. N. (2003). Subjective well-being Is desirable, but not the summum bonum. Workshop on Well-Being. Minneapolis: University of Minnesota.

Gunawan, I., Halim, M., \& Lihardja., N. (2011). Subjective well-being wanita dewasa madya survivor kanker payudara. ARKHE: Jurnal Ilmiah Psikologi, 16(1), 34-45. http:// catalogue.paramadina.ac.id//index.php?p=show_detail\&id=27171

Hamalik, O. (2003). Metode belajar dan kesulitan-kesulitan belajar. Bandung: Remaja Karya.

Hamama, L., Ronen, T., Shachar, K., \& Rosenbaum, M. (2013). Links between stress, positive and negative affect, and life satisfaction among teachers in Special Education Schools. Journal of Happiness Studies, 14(3), 731-751. https://doi.org/10.1007/s10902-0129352-4

Hapsari, I. I., \& Mardiana. (2016). Empati dan motivasi kerja guru Sekolah Luar Biasa. JPPP - Jurnal Penelitian dan Pengukuran Psikologi, 5(1), 48-56. https://doi.org/10.21009/ JPPP.051.07

Indriana, Y. (2012). Gerontologi dan progeria. Yogyakarta: Pustaka Pelajar.

Irianto, \& Subandi. (2015). Studi fenomenologis kebahagiaan guru di Papua. Gadjah Mada Journal of Psychology (GamaJop), 1(3), 140-166. https://jurnal.ugm.ac.id/gamajop/ article/view/8812/6683

Jannah, M., \& Darmawanti, I. (2004). Tumbuh kembang anak usia dini \& deteksi dini pada anak berkebutuhan khusus. Insight Indonesia.

Lopez, S. J., Pedrotti, J. T., \& Snyder, C. R. (2007). Positive psychology: The scientific and practical explorations of human. Sage Publications, Inc.

Lu, L., \& Shih, J. Bin. (1997). Sources of happiness: A qualitative approach. The Journal of Social Psychology, 137(2), 181-187. https://doi.org/10.1080/00224549709595429

Maulipaksi, D. (2017). Sekolah Inklusi dan pembangunan SLB dukung Pendidikan Inklusi. Kementrian Pendidikan dan Kebudayaan. Diambil dari https:/www.kemdikbud. go.id/main/blog/2017/02/sekolah-inklusi-dan-pembangunan-slb-dukung-pendidikaninklusi

Meiza, C. (2016). Perbedaan kebahagiaan pada guru berstatus PNS dan Honorer. Jurnal Ilmiah Psikologi, 9(2), 132-141. https://ejournal.gunadarma.ac.id/index.php/psiko/article/ view/1551

Mertoğlu, M. (2018). Happiness level of teachers and analyzing its relation with Some variables. 
Asian Journal of Education and Training, 4(4), 396-402. https://doi.org/10.20448/ journal.522.2018.44.396.402

Nandini, D. A. (2016). Kontribusi optimisme terhadap kebahagiaan pada karyawan. Jurnal Ilmiah Psikologi, 9(2), 187-196. https://ejournal.gunadarma.ac.id/index.php/psiko/ article/view/1557

Patnani, M. (2012). Kebahagiaan pada perempuan. Jurnal Psikogenesis, 1(1), 56-64. http:// academicjournal.yarsi.ac.id/index.php/Jurnal-Online-Psikogenesis/article/view/36/pdf

Peraturan Pemerintah (PP) tentang Pendidikan Luar Biasa no. 72, Pub. L. No. 72 (1991). https://peraturan.bpk.go.id/Home/Details/58418

Primasari, A., \& Yuniarti, K. W. (2012). What make teenagers happy? An exploratory study using indigenous psychology approach. International Journal of Research Studies in Psychology, 1(2), 53-61. https://doi.org/10.5861/ijrsp.2012.v1i2.80

Robbins, B. D. (2008). What is the good life? Positive psychology and the renaissance of humanistic psychology. The Humanistic Psychologist, 36(2), 96-112. https://doi. org/10.1080/08873260802110988

Rofi'udin. (2013). Konsep kebahagiaan dalam pandangan Psikologi Sufistik. Teologia, 24(2), 1-37. https://journal.walisongo.ac.id/index.php/teologia/article/view/332/301

Rosdiana. (2013). Guru SLB Tanjung Pinang. haluankepri.com. Diambil dari http://www. haluankepri.com/siape-die/46261-rosdiana guruslbtanjungpinang.html.

Seligman, M. E. P. (2005). Authentic happiness menciptakan kebahagiaan dengan psikologi positif. (E.Y. Nukman, Terjemahan). Bandung: Mizan.

Seligman, M. E. P. (2011). Flourish: A visionary new understanding of happiness and well-being. New York: Free Press.

Toisuta, D., \& Loekmono, J. . L. (2017). Hubungan kepuasan kerja, stres guru dengan kebahagiaan guru Pendidikan Agama Sekolah Menengah di Kota Ambon. Satya Widya, 33(1), 11-28. https://doi.org/10.24246/j.sw.2017.v33.i1.p11-28

Urrutia, J. D., Borja, P. C. R., Castillo, J. C. D., \& Magana, R. A. (2019). The relationships of happiness and job satisfaction to job performance of Public Secondary School teachers in Selected Schools in the Division of Cavite. International Journal of Recent Technology and Engineering, 8(2S11), 3198-3210. https://doi.org/10.35940/ijrte.B1419.0982S1119

Veenhoven, R. (1991). Is happiness relative? Social Indicators Research, 24, 1-34. https://link. springer.com/article/10.1007/BF00292648

Wardhani, D. T. (2012). Burnout di kalangan guru Sekolah Luar Biasa di Bandung. Jurnal Psikologi Undip, 11(1), 73-82. https://ejournal.undip.ac.id/index.php/psikologi/article/ view/5150/4671

Wulandari, S., \& Widyastuti, A. (2014). Faktor - faktor kebahagiaan di tempat kerja. Jurnal Psikologi, 10(1), 49-60. http://ejournal.uin-suska.ac.id/index.php/psikologi/article/ viewFile/1178/1070 